\title{
Perceptions, Knowledge, and Attitude Toward Mental Health Disorders and Their Treatment Among Students in an Indonesian University
}

This article was published in the following Dove Press journal: Psychology Research and Behavior Management

\author{
Irma M Puspitasari iD ${ }^{1,2}$ \\ Ingka Tisya Garnisa \\ Rano K Sinuraya (iD ${ }^{1,2}$ \\ Witriani Witriani (iD) ${ }^{3}$ \\ 'Department of Pharmacology and \\ Clinical Pharmacy, Faculty of Pharmacy, \\ Universitas Padjadjaran, Sumedang, \\ Indonesia; ${ }^{2}$ Center of Excellence in \\ Higher Education for Pharmaceutical \\ Care Innovation, Universitas Padjadjaran, \\ Sumedang, Indonesia; ${ }^{3}$ Department of \\ Educational Psychology, Faculty of \\ Psychology, Universitas Padjadjaran, \\ Sumedang, Indonesia
}

Purpose: To identify perception, knowledge, and attitudes toward mental health disorders and their treatment among students in a university in West Java, Indonesia.

Methods: A cross-sectional study which measures perceptions, knowledge, and attitudes of 427 university students using convenience sampling through a 53-item self-administered questionnaire was conducted in January 2020. Either a chi-square test or the Kruskal-Wallis test was employed to analyze the association between student characteristics and variables. Furthermore, Spearman rank correlation coefficient was utilized to evaluate the relationship between variables.

Results: A total of $51.29 \%$ students had negative perceptions, $50.23 \%$ had good knowledge, and $52.46 \%$ had positive attitudes toward mental disorders and their treatment. The differences in the experience of visiting a psychologist or psychiatrist were associated with perceptions $(P<0.01)$, knowledge $(P<0.01)$, and attitudes $(P<0.01)$. A positive correlation was observed between perception and attitude $(\mathrm{r}=0.56 ; P<0.01)$ and between knowledge and attitude $(\mathrm{r}=0.24 ; P<0.01)$. The students obtained most information about mental health from social media $(92.74 \%)$.

Conclusion: Students demonstrated good knowledge and positive attitude toward mental health disorders. However, some continue to hold negative perceptions regarding approaching someone with a mental disorder, encouraging doubt and fear. Health promotion about mental health disorders and their treatment must be conducted to increase positive perceptions, good knowledge, and positive attitudes of the students. Social media tools can be considered to enhance mental health promotion and prevention of mental health problems.

Keywords: behavior, students, mental health, health promotion

\section{Introduction}

Mental disorders are generally characterized by some combination of abnormal thoughts, emotions, behaviors, and relationships with others. ${ }^{1}$ Common mental disorder is a term incorporating depression, anxiety, adjustment disorders, and stress-related ill health, all of which have major consequences around the world. ${ }^{2}$ Mental disorders can cause suffering, pose a risk of social isolation, and threaten the personal income of individuals. ${ }^{2}$ Fortunately, most of these disorders can be successfully treated. ${ }^{1}$

The prevalence of mental disorders in Indonesia arose from 2013 to 2018 according to basic health research in 2018. As of August 2018, the population aged $>15$ years of Indonesia included approximately 194 million individuals, ${ }^{3}$ and
Correspondence: Irma M Puspitasari Department of Pharmacology and Clinical Pharmacy, Faculty of Pharmacy, Universitas Padjadjaran, Jalan Bandung Sumedang KM 21 , Jatinangor, Sumedang 45363, Indonesia

Tel +622284288888 Ext 3510

Email irma.melyani@unpad.ac.id 
there were 67 million households in $2017 .{ }^{4}$ The prevalence of schizophrenia in individuals aged $>15$ years in 2018 was approximately 470,000 people (seven of 1000 households have a member with schizophrenia), and the prevalence of mental-emotional disorders, including bipolar disorder, depression, and anxiety disorders, was approximately 19 million (9.8\%). ${ }^{5,6}$ Among these mental-emotional disorders, the prevalence of depression was approximately 11.8 million individuals $(6.1 \%))^{5,6}$

A strong social stigma is attached to mental health disorders, although many people have mental disorders. People with mental health problems can experience discrimination in all aspects of their lives. ${ }^{7}$ Furthermore, stigma may result in discrimination against people with mental disorders and prevent them from gaining two important opportunities to pursue their life goals: job opportunity and the opportunity to live independently and safely. ${ }^{8}$ Mental health disorders experienced by individuals are commonly underestimated because of the stigma involving the community; hence, people with mental disorders are isolated and do not want to seek treatment. If it continues, then people with mental disorders could not control themselves and choose to support life.

Suicide cases committed by students over the past few years in Indonesia have become mental health issues among students. Indonesian online media reported three cases of suicide in less than 3 months that occurred in students in a public university in West Java, Indonesia. ${ }^{9}$ A survey was also conducted in 2019 among college students in Bandung, which stated that $30.5 \%$ of students were depressed, $20 \%$ thought of killing themselves, and $6 \%$ had tried to struggle alone. ${ }^{10}$ Some influencing factors are academic stress, family problems, financial problems, problems in friendship, traumatic problems, mental disorders that have not been handled, immaturity of oneself, or personal problems. ${ }^{10}$

Perceptions entail a process through which individuals manage sensory information and interpret it. ${ }^{11}$ Knowledge pertains in acquiring, retaining, and using information to one's capacity. ${ }^{12}$ The nature of knowledge depends on different modes of idea acquisition, such as perception, imagination, memory, judgment, abstraction, and reasoning. ${ }^{12}$ Attitude refers to an individual's tendency to react to certain situations in particular ways, view and interpret events according to several tendencies, or organize opinions into coherent and interrelated structures. ${ }^{12}$ Perceptions, knowledge, and attitude are important in increasing students' awareness toward mental health problems.
A study on perceptions, knowledge, and attitudes toward mental health disorders has been conducted in various countries. A study in Saudi Arabia by Abolfotouh et $\mathrm{al}^{13}$ in 2019 validated that mental health perceptions in the Saudi Arabian Society are highly diverse and that knowledge is lacking. In 2018, Li et al's ${ }^{14}$ study asserted that negative attitudes toward mental disorders commonly occur among people in China. In addition, in 2016, Aruna et al's ${ }^{15}$ study corroborated that the population of medical undergraduate students also had considerable deficiencies in knowledge and attitudes related to psychiatric disorders, especially in the early years of education. However, to the best of our knowledge, there have been no studies conducted that focus on perceptions, knowledge, and attitudes toward mental health among students in Indonesia. The stigma of mental illness remains widespread among society and healthcare professionals in the country. ${ }^{16}$ Hence, it is crucial to increase knowledge via antistigma campaigns and public education through schools and the media. ${ }^{13-15}$ Accordingly, we recruited students in a university in West Java, Indonesia, and identified their perceptions, knowledge, and attitudes toward mental health disorders as well as their treatment to prepare a mental health educational campaign in the university.

\section{Materials and Methods \\ Study Design and Setting}

This cross-sectional study measured the perceptions, knowledge, and attitudes of university students through online selfadministered questionnaires and was conducted in a public university in West Java, Indonesia in January 2020. The university has more than 32,000 students and has 16 faculties including health and non-health faculties.

\section{Sample Size and Participants}

The participants for this study were recruited via convenience sampling. Based on Charan and Biswas's ${ }^{17}$ study, the sample size for the cross-sectional survey was calculated using a standard normal variate at 5\% type 1 error $(P<0.05)$, an expected population proportion of $50 \%$, and an absolute error of $5 \%$, with an additional $10 \%$ to prevent non-evaluable participants, yielding 424 required participants. The participants of this study were active students enrolled in the university, aged $>18$ years, who agreed to participate in this study. The respondents voluntarily participated, and their anonymity and confidentiality of information 
were ensured. Informed consent was acquired from the participants before they filled out the questionnaire.

\section{Ethics}

The ethics approval was obtained from the research ethics committee of Universitas Padjadjaran, no. 104/UN6. KEP/ EC/2020.

\section{Study Instruments}

Fifty-three item questions of the online form include demographic data, and three variable questionnaires, namely, perception, knowledge, and attitude, were adapted for measuring perceptions, knowledge, and attitudes among the students. The perception questionnaire was adapted from the studies of Abolfotouh et $\mathrm{al}^{13}$ and Sadik et al, ${ }^{18}$ which consisted of seven questions. The knowledge questionnaire was adapted from the study of Wang et al, ${ }^{19}$ which comprises 16 questions, and four modified questions about mental disorder treatment were also added, thereby resulting in 20 questions in total. The attitude questionnaire was adapted from the research of Wahl et al, ${ }^{20}$ that involves 17 questions.

Three questionnaires were translated by an English professional into Bahasa Indonesia and then were tested for face and content validity by experts in Public Health and Educational Psychology from Universitas Padjadjaran, Indonesia. A pilot study with 30 respondents was conducted to assess its accessibility and reliability. Additionally, Cronbach's alpha values were obtained for the instrument reliability, and all were in an acceptable range for perceptions, knowledge, and attitudes (0.69, 0.78 , and 0.78 , respectively). A little modification was needed after the pilot study, and the resulting data from the pilot study were excluded from the final results. The questionnaires were then available for data collection.

Perceptions toward people with mental disorders were assessed using seven statements with a Likert scale from 1 (strongly disagree) to 5 (strongly agree). Each respondent's scores were calculated, resulting in total perception scores ranging from 7 to 35 points. Because the data did not follow normal distribution, the participants' perceptions were classified based on the median score, which was 26 in this case. Therefore, scores $\geq 26$ corresponded to a positive perception, and scores $<26$ entailed a negative perception. The respondents' perception scores were also calculated and summed to determine the total.

In the knowledge questions, each response ("Yes," "No," and "Not sure") was assigned a score. Correct answers were given a score of 1, while incorrect responses and "Not sure" were scored 0 . The questionnaire scores ranged from 0 (minimum) to 20 (maximum). The respondents were then classified as having high knowledge if their scores were $\geq 14$ and having low knowledge if their scores were $<14$ (median=14). As with the aforementioned, the knowledge scores of each respondent were computed and summed to come up with the total knowledge score.

Meanwhile, the participants' attitudes toward people with mental disorders were assessed using 17 statements with a five-point Likert scale, where $1=$ strongly disagree and $5=$ strongly agree. The scores were calculated for each respondent, with the total scores ranging from 17-85 points. Attitudes were positive if the respondents' scores were $\geq 62$, and negative if their scores were $<62$ (median=62).

\section{Data Collection}

A research assistant was responsible for the data collection process. The data were obtained from the students in all faculties at the university by prearranged visit to student executive body offices through a contact person from each faculty. The students in the student executive body office who were interested to participate in the study were invited to fill out the online questionnaire. All the participants' responses were stored in an online database that only the authors could access and download from. The data were summarized in tables, excluding incomplete responses such as those with missing data.

\section{Statistical Analysis}

Descriptive statistics were used to describe the demographic characteristics of the respondents and summarized into tables. The Shapiro-Wilk test was applied to assess the data distribution. Either a chi-square test or the Kruskal-Wallis test was employed to analyze the association between student characteristics and variables. Furthermore, the Spearman rank correlation coefficient was utilized to evaluate the relationship between variables with $P$-value $<0.05$ considered as significant. Statistical Package for Social Sciences version 22 was used for the data analysis (IBM Corp., Armonk, NY, USA).

\section{Results}

\section{Characteristics of Students}

A total of 432 students agreed to become participants in this study. However, we excluded incomplete responses from five students; hence, the number of eligible respondents decreased to 427 . Table 1 presents the subject 
Table I Students' Characteristics

\begin{tabular}{|c|c|c|}
\hline \multicolumn{2}{|l|}{ Characteristics } & \multirow{2}{*}{$\begin{array}{l}\text { n (\%) } \\
327(76.58) \\
100(23.42)\end{array}$} \\
\hline Gender & $\begin{array}{l}\text { Female } \\
\text { Male }\end{array}$ & \\
\hline $\begin{array}{l}\text { Age } \\
\text { (Median: } 20 \text { years old) }\end{array}$ & $\begin{array}{l}\geq 20 \\
<20\end{array}$ & $\begin{array}{l}172(40.28) \\
255(59.72)\end{array}$ \\
\hline Faculty & $\begin{array}{l}\text { Health faculties } \\
\text { Non-health } \\
\text { faculties }\end{array}$ & $\begin{array}{l}185(43.33) \\
242(56.67)\end{array}$ \\
\hline Year of entering the university & $\begin{array}{l}2016 \\
2017 \\
2018 \\
2019 \\
2020\end{array}$ & $\begin{array}{l}\text { II } 0 \text { (25.76) } \\
\text { I } 27(29.74) \\
\text { II } \\
65 \text { (I5.26.70) } \\
\text { II (2.58) }\end{array}$ \\
\hline Academic degree & $\begin{array}{l}\text { Undergraduate } \\
\text { Postgraduate }\end{array}$ & $\begin{array}{l}403(94.38) \\
24(5.62)\end{array}$ \\
\hline $\begin{array}{l}\text { Have experience of talking with } \\
\text { a person with a mental disorder }\end{array}$ & $\begin{array}{l}\text { Yes } \\
\text { No }\end{array}$ & $\begin{array}{l}258(60.42) \\
169(39.58)\end{array}$ \\
\hline $\begin{array}{l}\text { Have been diagnosed with a mental } \\
\text { health disorder }\end{array}$ & $\begin{array}{l}\text { Yes } \\
\text { No }\end{array}$ & $\begin{array}{l}22(5.15) \\
405(94.85)\end{array}$ \\
\hline $\begin{array}{l}\text { Have visited a psychologist or } \\
\text { psychiatrist }\end{array}$ & $\begin{array}{l}\text { Yes } \\
\text { No }\end{array}$ & $\begin{array}{l}57(13.35) \\
370(86.65)\end{array}$ \\
\hline $\begin{array}{l}\text { Source of information about mental } \\
\text { health (can choose more than one } \\
\text { option) }\end{array}$ & $\begin{array}{l}\text { Social media } \\
\text { Formal } \\
\text { education } \\
\text { Environment } \\
\text { Books } \\
\text { Seminars }\end{array}$ & $\begin{array}{l}396(92.74) \\
198(46.37) \\
256(59.95) \\
5(1.17) \\
3(0.70)\end{array}$ \\
\hline
\end{tabular}

Notes: $\mathrm{n}=$ number of participants; $\%$ = percentage of participants.

characteristics. Most of the students were female $(n=327$, $76.58 \%)$ and were in undergraduate programs $(n=403$, $94.38 \%)$. A total of $60.42 \%(\mathrm{n}=258)$ respondents experienced talking to people with mental health disorders, $13.35 \%$ had visited mental health professionals, and $5.15 \%$ had been diagnosed with a mental health disorder. The students obtain most information about mental health from social media (92.74\%) and from their environment, such as family and friends (59.95\%).

\section{Perceptions of Students Regarding Mental Health Disorders}

Table 2 illustrates the perceptions of the students towards people with mental disorders. Overall, 219 (51.29\%) students had negative perceptions towards mental health disorders, and 208 (48.71\%) respondents had positive perceptions. Most of the respondents agreed and strongly agreed with the perceptions that people with mental health problems tend to be blamed for their conditions (item number $1 ; 55.87 \%$ ), that individuals with mental disorders can work (item number $4 ; 64.88 \%$ ), and that anyone can suffer from a mental illness (item number 6; 92.03\%). Conversely, some of the respondents disagreed and strongly disagreed with the perceptions that one can tell whether an individual has a mental health disorder through his/her physical appearance (item number 2; 57.85\%), that people with mental disorders can make friends (item number $3 ; 51.29 \%$ ), that they are commonly dangerous (item number $5 ; 59.48 \%$ ), and that they are insane (item number $7 ; 88.99 \%)$.

\section{Knowledge of Students Concerning Mental Health Disorders}

Table 3 illustrates the responses of the respondents to knowledge towards mental health. Overall, 215 (50.35\%) students had good knowledge about mental health disorders, and 212 (49.65\%) had poor knowledge. Of the 20 questions, the majority of the respondents answered correctly on the following items: 1) the normalization of psychological problems and mental disorders (item numbers $1,3,7,8,11,12,15$, and 16), 2) mental health is part of an overall well-being (item number 5), and 3) mental disorders are uncommon and unchangeable (item numbers $6,9,13$, and 14).

In the items on the treatment of mental health disorders (item numbers 17, 18, 19, and 20), most of the respondents answered correctly, except for the type of antidepressant drugs (number 20), and only $28.13 \%$ of the students answered correctly. The knowledge about incorrect beliefs about causes of mental disorders (item numbers 2 and 4) were correctly answered by only $20.84 \%$ and $43.56 \%$ of students, respectively. About $44.03 \%$ of respondents answered correctly on item 10 , which asked about schizophrenia treatment.

\section{Attitudes of Students Toward Mental Health Disorders}

Table 4 illustrates the attitudes of the students towards people with mental disorders. Overall, 224 (52.46\%) students had positive attitudes towards mental health disorders, and 203 (47.54\%) had negative attitudes towards mental health disorders. Most of the students agreed and strongly agreed with the attitude that people with mental health disorders deserve respect (item 
Table 2 Students' Perceptions

\begin{tabular}{|c|c|c|c|c|c|c|}
\hline \multirow[t]{2}{*}{ No. } & \multirow[t]{2}{*}{ Items } & SA & A & $\mathbf{N}$ & D & SD \\
\hline & & n (\%) & n (\%) & n (\%) & n (\%) & n (\%) \\
\hline 1 & $\begin{array}{l}\text { People with mental health problems tend to be blamed for their } \\
\text { conditions. }\end{array}$ & $32(7.49)$ & $207(48.48)$ & $55(12.88)$ & III (26.00) & $22(5.15)$ \\
\hline 2 & $\begin{array}{l}\text { One can tell whether an individual has a mental health disorder } \\
\text { through his/her physical appearance. }\end{array}$ & $6(I .4 I)$ & $76(17.80)$ & $98(22.95)$ & $176(41.22)$ & $71(16.63)$ \\
\hline 3 & People who are mentally ill cannot make friends. & $3(0.70)$ & $63(14.75)$ & $142(33.26)$ & I $70(39.81)$ & 49 ( 11.48$)$ \\
\hline 4 & People with mental illnesses can work. & $42(9.84)$ & $235(55.04)$ & $107(25.06)$ & $37(8.67)$ & $6(I .4 I)$ \\
\hline 5 & People with mental illnesses are commonly dangerous. & $5(1.17)$ & $50(11.71)$ & II 18 (27.63) & $220(5 \mid .52)$ & $34(7.96)$ \\
\hline 6 & Anyone can suffer from a mental illness. & $156(36.53)$ & $237(55.50)$ & $23(5.39)$ & $9(2.11)$ & $2(0.47)$ \\
\hline 7 & People with mental illnesses are insane. & $\mathrm{I}(0.23)$ & $10(2.34)$ & $36(8.43)$ & I9I (44.73) & $189(44.26)$ \\
\hline
\end{tabular}

Notes: $\mathrm{n}=$ number of participants; $\%$ = percentage of participants.

Abbreviations: SA, strongly agree; A, agree; N, neither agree nor disagree; D, disagree; SD, strongly disagree.

number $1 ; 98.13 \%)$, that we must help people with mental illnesses for them to be better (item number 2; $96.25 \%$ ), that a mockery of mental disorders is painful (item number $3 ; 98.13 \%$ ), that someone with a mental illness can be a good friend (item number 17; 62.53\%), and that learning about mental illnesses is crucial (item number $4 ; 98.83 \%$ ). Contrarily, most of the respondents disagreed and strongly disagreed with the attitude that people with mental health disorders should be avoided (item number $5 ; 78.69 \%$ ), that students with mental illnesses should not be in regular classes (item number 14; $60.4 \%$ ), that if any of their friends suffer from mental illnesses, they would advise them not to tell anyone (item number $10 ; 63 \%$ ), that having a mental illness is

Table 3 Students' Knowledge

\begin{tabular}{|c|c|c|c|}
\hline No. & Items & $\begin{array}{l}\text { Correct } \\
\text { Answers }\end{array}$ & $\%$ \\
\hline I & Exercise can help maintain mental health [yes]. & 372 & 87.12 \\
\hline 2 & Mental disorders are caused by wrong way of thinking [no]. & 89 & 20.84 \\
\hline 3 & Many people have psychiatric problems, but they do not realize them [yes]. & 371 & 86.89 \\
\hline 4 & External stress factors are the causes of all types of mental health disorders [no]. & 186 & 43.56 \\
\hline 5 & $\begin{array}{l}\text { The components of mental health include normal intelligence, stable moods, positive attitudes, interpersonal } \\
\text { relationships, and quality adaptability [yes]. }\end{array}$ & 376 & 88.06 \\
\hline 6 & The majority of mental disorders cannot be cured [no]. & 220 & 51.52 \\
\hline 7 & $\begin{array}{l}\text { Psychological or psychiatric services should be sought if one suspects the presence of psychological problems } \\
\text { or mental disorders [yes]. }\end{array}$ & 388 & 90.87 \\
\hline 8 & Psychological problems can occur at almost all ages [no]. & 402 & 94.15 \\
\hline 9 & Mental disorders and psychological problems cannot be prevented [no]. & 300 & 70.26 \\
\hline 10 & $\begin{array}{l}\text { In severe mental disorders (eg, schizophrenia), treatment is only given within a certain period of time and } \\
\text { should not be given for a long period of time [no]. }\end{array}$ & 188 & 44.03 \\
\hline II & The main symptom of schizophrenia is hallucination [yes]. & 270 & 63.23 \\
\hline 12 & $\begin{array}{l}\text { Individuals who have a family history of mental disorders have a higher risk of experiencing psychological } \\
\text { problems and mental disorders [yes]. }\end{array}$ & 233 & 54.57 \\
\hline 13 & Psychological problems in adolescents do not affect academic grades [no]. & 337 & 78.92 \\
\hline 14 & Middle-aged or elderly individuals rarely have psychological problems and mental disorders [no]. & 267 & 62.53 \\
\hline 15 & Individuals with bad temperament are more likely to have psychiatric problems [yes]. & 222 & 51.99 \\
\hline 16 & Feelings of sadness and depression are the same [no]. & 388 & 90.87 \\
\hline 17 & The treatment of people with mental health disorders is enough by giving antidepressants [no]. & 348 & 81.50 \\
\hline 18 & The treatment of people with mental health disorders needs supportive psychological therapy [yes]. & 400 & 93.68 \\
\hline 19 & Mental health medications do not provide considerable adverse effects [no]. & 228 & 53.40 \\
\hline 20 & Sertraline is one of the antidepressants [yes]. & 121 & 28.13 \\
\hline
\end{tabular}

Note: $\%=$ percentage of correct responses. 
Table 4 Students' Attitudes

\begin{tabular}{|c|c|c|c|c|c|c|}
\hline \multirow[t]{2}{*}{ No. } & \multirow[t]{2}{*}{ Items } & SA & A & $\mathbf{N}$ & D & SD \\
\hline & & n (\%) & n (\%) & n (\%) & n (\%) & n (\%) \\
\hline I & People with mental illnesses deserve respect. & $274(64.17)$ & $145(33.96)$ & $7(1.64)$ & $\mathrm{I}(0.23)$ & 0 \\
\hline 2 & We must help people with mental illnesses for them to be better. & $225(52.69)$ & $186(43.56)$ & $13(3.04)$ & $3(0.70)$ & 0 \\
\hline 3 & A mockery of mental disorders is painful. & $257(60.19)$ & $162(37.94)$ & $5(1.17)$ & $3(0.70)$ & 0 \\
\hline 4 & Learning about mental illnesses is crucial. & $231(54.10)$ & $191(44.73)$ & $4(0.94)$ & 0 & $\mathrm{I}(0.23)$ \\
\hline 5 & Avoiding people with mental illnesses is a good idea. & $5(1.17)$ & $13(3.04)$ & $73(17.10)$ & $236(55.27)$ & $100(23.42)$ \\
\hline 6 & I feel comfortable when encountering people with mental illnesses. & $4(0.94)$ & $71(16.63)$ & $250(58.55)$ & $93(21.78)$ & $9(2.11)$ \\
\hline 7 & People with mental illnesses can help others. & $40(9.37)$ & $206(48.24)$ & $162(37.94)$ & $18(4.22)$ & $\mathrm{I}(0.23)$ \\
\hline 8 & I am scared when being approached by people with mental illnesses. & $7(1.64)$ & $62(14.52)$ & $152(35.60)$ & $182(42.62)$ & $24(5.62)$ \\
\hline 9 & When I have a mental health disorder, I most likely do not tell my friends. & $33(7.73)$ & $128(29.98)$ & $130(30.44)$ & $116(27.17)$ & $20(4.68)$ \\
\hline 10 & $\begin{array}{l}\text { If any of my friends suffer from mental illnesses, then I would advise them not to tell } \\
\text { anyone. }\end{array}$ & $10(2.34)$ & $44(10.30)$ & $104(24.36)$ & $188(44.03)$ & $81(18.97)$ \\
\hline 11 & Caring for people with mental illnesses in hospitals makes the community feel safer. & $29(6.79)$ & $176(41.22)$ & $161(37.70)$ & $53(|2.4|)$ & $8(1.87)$ \\
\hline 12 & $\begin{array}{l}\text { Only people who are weak and overly sensitive let themselves be affected by mental } \\
\text { illnesses. }\end{array}$ & $15(3.51)$ & $49(11.48)$ & $80(18.74)$ & $177(41.45)$ & $106(24.82)$ \\
\hline 13 & It would be a shame if I had a mental illness. & $20(4.68)$ & $85(19.91)$ & $105(24.59)$ & $168(39.34)$ & 49 ( 11.48$)$ \\
\hline 14 & Students with mental illnesses should not be in regular classes. & $8(1.87)$ & $49(11.48)$ & $112(26.23)$ & $179(41.90)$ & $79(18.50)$ \\
\hline 15 & I have a little in common with people suffering from mental health disorders. & $8(1.87)$ & $46(10.77)$ & $125(29.27)$ & $17 \mid(40.05)$ & $77(18.03)$ \\
\hline 16 & Students with mental illnesses need a special curriculum in learning. & $28(6.56)$ & $146(34.19)$ & $166(38.88)$ & $66(15.46)$ & $21(4.92)$ \\
\hline 17 & Someone with mental illnesses can be a good friend. & $57(13.35)$ & $210(49.18)$ & $145(33.96)$ & $13(3.04)$ & $2(0.47)$ \\
\hline
\end{tabular}

Notes: $\mathrm{n}=$ number of participants; \% = percentage of participants.

Abbreviations: SA, strongly agree; $A$, agree; $N$, neither agree nor disagree; $D$, disagree; SD, strongly disagree.

shameful (item number $13 ; 50.82 \%$ ), and that they have little in common with people suffering from mental health disorders (item number $15 ; 58.08 \%$ ).

\section{Association Between Student Characteristics and Perceptions, Knowledge, and Attitudes Toward Mental Health Disorders}

Table 5 shows the association between student characteristics and perceptions, knowledge, and attitudes. The gender differences were associated with attitudes toward mental health disorders $(P<0.05)$. The female students tended to have 1.5 -times positive attitudes $(\mathrm{OR}=1.51 ; 0$.96-2.39) towards people with mental health disorders.

The age and faculty differences were associated with knowledge $(P<0.01)$. The respondents whose age was $\geq 20$ tended to have 2.5-times higher knowledge than those whose age was $<20(\mathrm{OR}=2.52 ; 1.70-3.78)$, whereas the students from the health faculty had 8-times higher knowledge than those who were not from there $(\mathrm{OR}=8.90$; 5.69-13.93).

The differences in educational levels were associated with knowledge $(P<0.01)$. The professional and postgraduate respondents tended to have 25-times better knowledge $(\mathrm{OR}=25.26 ; 3.38-188.95)$.
The differences in the experience of talking with persons with mental disorders were associated with perceptions $(P<0.01)$ and attitudes $(P<0.01)$. Those who experienced talking with individuals with mental disorders tended to have 1.5 -times more positive perceptions $(\mathrm{OR}=1.58 ; 1.07-2.34)$ and 1.8-times more positive attitudes $(\mathrm{OR}=1.83 ; 1.23-2.72)$ towards people with mental health disorders.

The differences in the experience of visiting a psychologist or psychiatrist were associated with perceptions $(P<0.01)$, knowledge $(\mathrm{P}<0.01)$, and attitudes $(P<0.01)$. Those who experienced visiting a psychologist or psychiatrist tended to have 2.2-times more positive perceptions $(\mathrm{OR}=2.29 ; 1.26-4.14)$, 3.9-times better knowledge $(\mathrm{OR}=3.93$; $(2.05-7.56)$, and 2-times more positive attitudes $(\mathrm{OR}=2.15 ; 1.21-3.83)$ towards people with mental health disorders than those who had not visited one.

\section{Relation Among Students' Perceptions, Knowledge, and Attitudes Regarding Mental Health Disorders}

Table 6 presents the relationship among the identified variables. The correlations revealed significant positive correlations between perceptions and attitudes $(\mathrm{r}=0.56$, $P<0.01)$ and between knowledge and attitudes $(\mathrm{r}=0.24$, $P<0.01)$. 


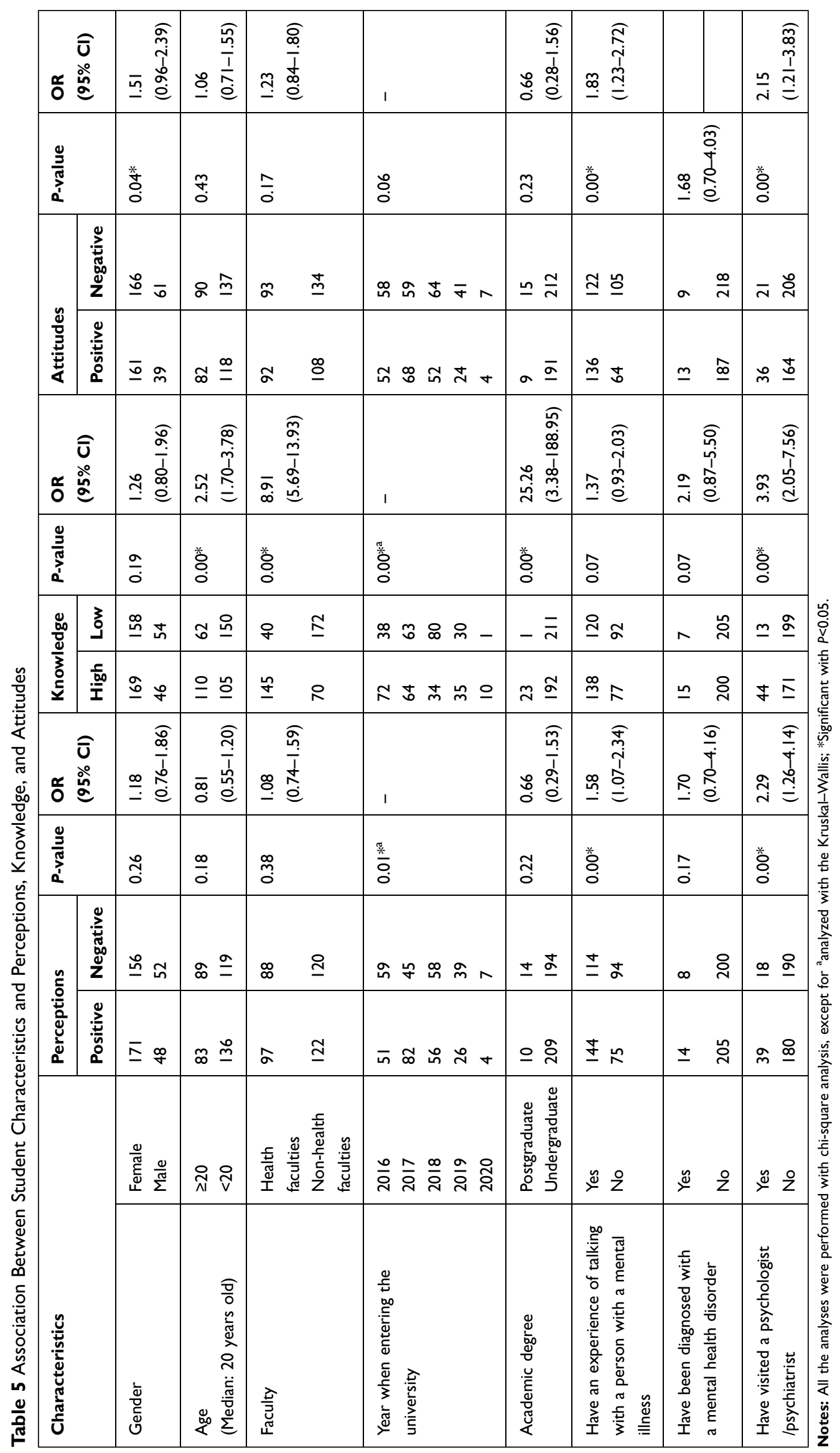


Table 6 Correlation Among Perceptions, Knowledge, and Attitudes

\begin{tabular}{|l|l|l|}
\hline Variables & Correlation Coefficient (r) & P-value \\
\hline Perception - knowledge & 0.06 & 0.10 \\
Perception - attitude & 0.56 & $0.00^{*}$ \\
Knowledge - attitude & 0.24 & $0.00^{*}$ \\
\hline
\end{tabular}

Note: *Correlation is significant at the 0.01 level (I-tailed).

\section{Discussion}

This study demonstrated the perceptions, knowledge, and attitudes of students toward mental disorders and their treatment in a university in Indonesia. A total $51.29 \%$ students had negative perceptions, $50.23 \%$ had good knowledge, and $52.46 \%$ had positive attitudes. This is in line with the results of the study of Riffel and Chen, ${ }^{21}$ where students demonstrate that the knowledge of mental health disorders in general is good and behaves most positively.However, some students still have negative perceptions that encourage doubt and fear to approach someone with a mental disorder. ${ }^{21}$ Health promotions about mental health disorders and their treatment must be conducted by educators, health workers, and university institutions to dispel the myths to help reduce negative perceptions and improve the care and treatment of people with mental disorders.

In this study, differences in age, education level, and faculty were associated with knowledge $(P<0.01)$; that is, students who were older, achieved a higher level of education, and belonged to the health faculty displayed better knowledge of mental health disorders. This is in accordance with the study of Aruna ${ }^{9}$ that validated that insufficient knowledge in students related to psychiatric disorders is present in the early years of education. In addition, the majority of the non-health faculty students did not know specific things about risk factors and their treatment, although general knowledge about mental health disorders was able to answer precisely because the respondents from the non-health faculty did not formally receive knowledge about psychiatry and mental health disorder treatment. This is consistent with the study of Tye, ${ }^{22}$ where the knowledge of the students of health faculties is higher than that of non-health faculties.

This study also found an association between gender differences and attitudes towards mental health disorders $(P<0.05)$; specifically, female students were more tolerant of people with mental disorders. A more positive view of female students toward mental health disorders might be due to their comparatively optimistic attitudes about the treatability of mental illnesses. ${ }^{23}$ This is in accordance with the studies of Pascucci et $\mathrm{al}^{24}$ and Smith et $\mathrm{al}^{25}$ that confirmed that women tend to show more tolerant attitudes toward people with mental disorders and have more tolerant attitudes than men. However, another study reported that men have better attitudes toward mental illnesses than women and that most women are afraid and do not want to be friends with those who are suffering from mental health disorders. ${ }^{26}$

This study further found that differences in experience of interacting with people with mental disorders were associated with perceptions $(P<0.01)$ and attitudes $(P<0.01)$. Particularly, students who have experienced contact with people with mental disorders had more positive perceptions and attitudes toward mental health disorders. This is supported by the research conducted by Doumit et $\mathrm{al}^{27}$ that asserted that being close with people with mental illnesses shows low stigma, better knowledge, and positive attitudes. Smith et $\mathrm{a}^{25}$ corroborated that knowledge about schizophrenia and personal family experiences with mental illnesses have the same scores on tolerance. The experience of contacting people with mental disorders showed positive changes, such as changing views on perceptions and the development of empathy. ${ }^{21}$

Another finding here is the association between differences in experiences visiting a psychologist or psychiatrist and perceptions $(P<0.01)$, knowledge $(P<0.01)$, and attitudes $(P<0.01)$. That is, students who have visited a psychologist or psychiatrist had better perceptions, knowledge, and attitudes towards mental health disorders. The reason might be that by having an experience of visiting a professional (psychologist or psychiatrist), students will understand more about mental health from the explanation that they obtain from the professional, which increases their knowledge. Samari et $\mathrm{al}^{28}$ reported that someone who specializes in psychiatry has a better attitude toward mental health, and Benti et $\mathrm{al}^{29}$ also affirmed that low perceptions occur in those who are less educated, unable to fully access information about mental health disorders, and have no family history of mental health disorders.

Our results validated a positive correlation between perceptions and attitudes $(\mathrm{r}=0.56, P<0.01)$ and between knowledge and attitudes $(\mathrm{r}=0.24, P<0.01)$. They further confirmed that students' perceptions and knowledge could affect their attitudes toward mental health disorders. The positive correlation in this study is in line with the study of Aguiniga et $\mathrm{al}^{30}$ that reported that students' perceptions of the media portrayal of mental illnesses have an influence on the attitudes of students. Furthermore, the 
positive correlation between knowledge and attitudes in this study is in line with the study of Aljedaani ${ }^{31}$ that showed a positive correlation between knowledge and attitudes among people in Jeddah City toward patients with mental illnesses. The study of Sher and $\mathrm{New}^{32}$ also affirmed that the experience of obtaining education increases the attitudes of students toward psychiatry.

To increase university students' awareness of their mental health, gaining insight into the gaps in perceptions, knowledge, and attitudes regarding mental health disorders and how they are treated is needed. Perceptions and attitudes are two factors that affect an individual's everyday life. ${ }^{33}$ Perceptions entail an individual's process of confronting a situation or stimuli and then interpreting the stimuli into something meaningful based on experience. ${ }^{34}$ Meanwhile, attitudes refer to an individual's tendency to act a certain way depending on their experiences, which include feelings, thoughts, and actions. ${ }^{34}$ Attitudes help us define our respective outlooks regarding certain situations as well as determine our behavior toward a specific situation or object. ${ }^{34}$ Knowledge can lead to the gradual development of healthy beliefs and attitudes, which are then reinforced by adopting healthy behaviors. ${ }^{35}$ Therefore, evaluating students' perceptions, knowledge, and attitudes could help identify attributes that shape healthy practices and responsive behaviors as well as strengthen prevention efforts against serious mental health problems.

A total of $92.74 \%$ of the respondents in this study obtain information on health problems from social media. The use of social media can be considered for the promotion and prevention of mental health disorders. Health campaigns and promotions can increase the awareness of the causes and treatment of mental health disorders in the general population. ${ }^{36}$

This study is limited by several factors. First, because it was conducted in only one university in Indonesia, its results are not generalizable to other universities in the country and are not representative of the perceptions, knowledge, and attitudes of all Indonesian university students. Second, the fact that the study sample included students who reported being diagnosed with mental health disorders could present a potential bias to the results. Nevertheless, no difference was observed regarding perceptions, knowledge, and attitudes between students who have had such diagnoses and those who have not. This means that the study may present university students' perceptions, knowledge, and attitudes toward mental health disorders.

\section{Conclusion}

The students generally displayed good knowledge and positive attitudes toward mental disorders and their treatment. However, some of them maintained negative perceptions regarding how to approach an individual with a mental disorder, which resulted in doubt and fear. Differences in age, education level, and faculty affiliation were associated with knowledge of mental disorders. Gender differences were also linked with students' attitudes toward mental disorders. Additionally, differences in experiences of interacting with people with mental disorders were associated with perceptions and attitudes. The experience of visiting a psychologist or psychiatrist influenced the perceptions, knowledge, and attitudes of the students. A positive correlation was observed between perceptions and attitudes and between knowledge and attitudes. Awareness programs and campaigns focusing on mental health disorders and their treatment must be implemented to increase students' perceptions, knowledge, and attitudes. Social media can also be considered to disseminate information on mental health as well as prevention efforts.

\section{Funding}

This work was supported by the Ministry of Research and Technology/National Agency for Research and Innovation, Indonesia (grant number 1827/UN6.3.1/LT/2020).

\section{Disclosure}

The authors declare that they have no competing interests.

\section{References}

1. World Health Organization. Mental Health. Available from: https:// www.who.int/mental_health/management/en/. Accessed October 2, 2020. Accessed April 9, 2020.

2. Axen I, Bjork Bramberg E, Vaez M, Lundin A, Bergstrom G. Interventions for common mental disorders in the occupational health service: a systematic review with a narrative synthesis. Int Arch Occup Environ Health. 2020;93:823-838. doi:10.1007/s00420-020-01535-4

3. Statistics Indonesia. Population 15 years of age and over by age group and type of activity during the previous week, 20082018; Published 2019. Available from: https:/www.bps.go.id/statictable/2016/04/04/ 1904/penduduk-berumur-15-tahun-ke-atas-menurut-golongan-umurdan-jenis-kegiatan-selama-seminggu-yang-lalu-2008 - 2018.html. Accessed November 25, 2019.

4. Statistik BP. Statistical Yearbook of Indonesia. (Sub-directorate of Statistical Compilation and Publication, ed.); 2018.

5. Ministry of Health Republic of Indonesia. National report basic health research 2018.; 2018. Available from: http://labmandat.litbang.depkes. go.id/images/download/laporan/RKD/2018/Laporan_Nasional_ RKD2018_FINAL.pdf.

6. Puspitasari IM, Sinuraya RK, Rahayu C, et al. Medication profile and treatment cost estimation among outpatients with schizophrenia, bipolar disorder, depression, and anxiety disorders in Indonesia. Neuropsychiatr Dis Treat. 2020;16:815-828. doi:10.2147/NDT. S240058 
7. Stigma and discrimination; Published 2015. Available from: https:// www.mentalhealth.org.uk/a-to-z/s/stigma-and-discrimination.Accessed April 9, 2020.

8. Hartini N, Fardana NA, Ariana AD, Wardana ND. Stigma toward people with mental health problems in Indonesia. Psychol Res Behav Manag. 2018;11:535-541. doi:10.2147/PRBM.S175251

9. Putra W. Three unpad students suicide, psychiatrist reveals the causes; Published 2019. Available from: https://news.detik.com/ber ita-jawa-barat/d-4463416/tiga-mahasiswa-unpad-bunuh-diri-psikiater -ungkap-penyebabnya. Accessed July 21, 2020.

10. Susanti R "20 percent of students in bandung think seriously for suicide." Available from: https://bandung.kompas.com/read/2019/10/ 12/19563181/20-persen-mahasiswa-di-bandung-berpikir-serius-untuk -bunuh-diri?page=all. Accessed October 2, 2020.

11. Beyerl K, Putz O, Breckwoldt A. The role of perceptions for community-based marine resource management. Front Mar Sci. 2016;3:238. doi:10.3389/fmars.2016.00238

12. Badran IG, Knowledge, attitude and practice the three pillars of excellence and wisdom: a plae in the medical profession. East Mediterr Heal J. 1995;1(1):8-16. doi:10.26719/1995.1.1.8

13. Abolfotouh MA, Almutairi AF, Almutairi Z, et al. Attitudes toward mental illness, mentally ill persons, and help-seeking among the Saudi public and sociodemographic correlates. Psychol Res Behav Manag. 2019;12:45-54. doi:10.2147/PRBM.S191676

14. Li J, Zhang MM, Zhao L, Li WQ, Mu JL, Zhang ZH. Evaluation of attitudes and knowledge toward mental disorders in a sample of the Chinese population using a web-based approach. BMC Psychiatry. 2018;18(1):367. doi:10.1186/s12888-018-1949-7

15. Aruna G, Mittal S, Yadiyal MB, Acharya C, Acharya S, Uppulari C. Perception, knowledge, and attitude toward mental disorders and psychiatry among medical undergraduates in Karnataka: A cross-sectional study. Indian $J$ Psychiatry. 2016;58(1):70-76. doi:10.4103/0019-5545.174381

16. Subu MA, Holmes D, Elliott J, Jacob JD. Persistent taboo: understanding mental illness and stigma among indonesian adults through grounded theory. Asian J Pharmacy, Nurs Med Sci. 2017;5(1).

17. Charan J, Biswas T. How to calculate sample size for different study designs in medical research? Indian J Psychol Med. 2013;35 (2):121-126. doi:10.4103/0253-7176.116232

18. Sadik S, Bradley M, Al-Hasoon S, Jenkins R. Public perception of mental health in Iraq. Int $J$ Ment Health Syst. 2010;4:1-11. doi:10.1186/1752-4458-4-26

19. Wang J, He Y, Jiang Q, et al. Mental health literacy among residents in Shanghai. Shanghai Arch Psychiatry. 2013;25(4):224-235. doi:10.3969/j.issn.1002-0829.2013.04.004

20. Wahl O, Susin J, Lax A, Kaplan L, Zatina D. Knowledge and attitudes about mental illness: A survey of middle school students. Psychiatr Serv. 2012;63(7):649-654. doi:10.1176/appi.ps.201100358

21. Riffel T, Chen SP. Exploring the knowledge, attitudes, and behavioural responses of healthcare students towards mental illnessesA qualitative study. Int J Environ Res Public Health. 2020;17 (1):1-11. doi:10.3390/ijerph17010025
22. Tye J Predictors of faculty intentions to refer students with mental health concerns to mental health professionals; 2016. Available from: https://www.semanticscholar.org/paper/Predictors-of-FacultyIntentions-to-Refer-Students-Tye/e273ffb9ee86e6ce1804012d4ade 7 d4aa7bd8d37. Accessed May 27, 2020.

23. Savrun BM, Arikan K, Uysal O, et al. Gender effect on attitudes towards the mentally ill: a survey of Turkish university students. Isr J Psychiatry Relat Sci. 2007;44(1):57-61.

24. Pascucci M, La Montagna M, Di Sabatino D, et al. Stigma and attitudes towards mental illness: gender differences in a sample of Italian medical students. Eur Psychiatry. 2017;41:S739-S739. doi:10.1016/j.eurpsy.2017.01.1359

25. Smith V, Reddy J, Foster K, et al. Public perceptions, knowledge and stigma towards people with schizophrenia. J Public Mental Health. 2011;10:45-56. doi:10.1108/17465721111134547

26. Bener A, Ghuloum S. Gender differences in the knowledge, attitude and practice towards mental health illness in a rapidly developing Arab society. Int J Soc Psychiatry. 2010. doi:10.1177/0020764010374415

27. Doumit CA, Haddad C, Id HS, et al. Knowledge, attitude and behaviors towards patients with mental illness: results from a national Lebanese study. PloS one. 2019:1-16. doi:10.1371/journal.pone.0222172

28. Samari E, Seow E, Chua BY, et al. Attitudes towards psychiatry amongst medical and nursing students in Singapore. BMC Med Educ. 2019;19(1):91. DOI:10.1186/s12909-019-1518-x

29. Benti M, Ebrahim J, Awoke T, Yohannis Z, Bedaso A. Community perception towards mental illness among residents of Gimbi Town, Western Ethiopia. Psychiatry J. 2016;2016:1-8. doi:10.1155/2016/ 6740346

30. Aguiniga DM, Madden EE, Zellmann KT. An exploratory analysis of students' perceptions of mental health in the media. Soc Work Ment Health. 2016;14(4):428-444. doi:10.1080/15332985.2015.1118002

31. Aljedaani SM. Adults ' knowledge, attitudes, and willingness to interact with patients suffering from mental illness in Jeddah City. $J \mathrm{Am}$ Psychiatr Nurses Assoc. 2018;25(5):360-375. doi:10.1177/10783903 18792610

32. Sher L, New AS. Understanding the role of psychiatric principles in patient care: an important goal of the medical student clerkship in psychiatry. Front Public Health. 2016;4(February):28-31. doi:10.3389/ fpubh.2016.00030

33. Özbaş S. The high school students' perceptions and attitudes toward bioenergy. Int J Environ Sci Educ. 2016;11(10):3201-3214.

34. Pickens J. Attitudes and Perceptions. In: Organizational Behaviour in Health Care. Borkowski N, editor. Miami: Jones and Bartlett Publishers; 2005:43-76.

35. Liu L, Liu Y-P, Wang J, An L-W, Jiao J-M. Use of a knowledge-attitude-behaviour education programme for Chinese adults undergoing maintenance haemodialysis: randomized controlled trial. J Int Med Res. 2016;44(3):557-568. doi:10.1177/ 0300060515604980

36. Choudhry F. Beliefs and perception about mental health issues: a meta-synthesis. Neuropsychiatr Dis Treat. 2016;12:2807-2818. doi:10. 2147/NDT.S111543
Psychology Research and Behavior Management

\section{Publish your work in this journal}

Psychology Research and Behavior Management is an international, peer-reviewed, open access journal focusing on the science of psychology and its application in behavior management to develop improved outcomes in the clinical, educational, sports and business arenas. Specific topics covered in the journal include: Neuroscience, memory and decision making; Behavior modification and management; Clinical applications; Business and sports performance management; Social and developmental studies; Animal studies. The manuscript management system is completely online and includes a very quick and fair peer-review system, which is all easy to use. Visit http://www. dovepress.com/testimonials.php to read real quotes from published authors. 